\title{
THOUGHTS
}

\section{Role reversal}

Eliseu Martins

Emeritus Professor at the School of Economics, Business, and Accounting of the University of São Paulo and Professor at the Department of Accounting of the School of Economics,

Business, and Accounting of Ribeirão Preto of the University of São Paulo

E-mail: emartins@usp.br

I have already written a few times, and I have spoken much more in public, that I have been discussing accounting theory much more often with regulatory agencies (such as the Accounting Standards Committee - CPC) than at the academy. And I usually discuss theory topics in any subject I teach! We know that, in recent times, studies on theory have taken place, or at least they have been disclosed, much more often at the professional environment than at the academy.

In the academic world, at least in the current positivist portion, almost everyone investigates by using econometric tools and taking the spirit of quantitative empiricism, without developing or proposing any new idea, new theory, new concept. In fact, we know that some purely theoretical and conceptual researches and discussions take place, some texts are even written up, but almost none of that comes up, also because scientific journals rarely publish them. (That is why another journal has just been created, Revista Fipecafi, for this purpose.)

However, even being aware that this is a very significant fact in many other countries, it was not a matter of surprise to me that three articles published by Accounting, Economics and Law - A Convivium, on February 2014, address the same issue. The first of them (p. 17-26), by Jonathan Glover, has a really exciting title: Have academic accountants and financial accounting standard setters traded places? A hard punch to the liver, mainly looking at the North American environment: have accounting scholars and standard setters switched places? The second article, by Richard Macve, Trading places: A UK (and IFRS) comment, takes the analysis of the previous article further by showing that, as it is known, in the English world the trend is the same, but to a lesser extent (it is worth noticing that this very journal published such material). The third article, by Stephen A. Zeff, former editor of Accounting Review, our old fellow, who has visited more than once the School of Economics, Business, and Accounting of the University of São Paulo (FEA/USP), entitled Some Historical Reflections on "Have academic and the standard setters traded places?", shows back and forth movements from one world to the other in publications by the American Accounting Association. Indeed, this is a major problem around the world and it seems to be a matter of concern. There is nothing wrong with the intercommunication between standard setters and theorists, quite the contrary. In fact, what is wrong is not the intercommunication, but the lack of it! However, the worst thing is this apparent exchange of positions.

The revolution of the so-called positivist accounting research, which started in the 1960s and 1970s and became strong in the next decade in the USA and in Brazil, intro- duced in a systematized way by Prof. Sérgio de Iudícibus in the 1990s, has gone far beyond where it should have gone (certainly, in our case, through no fault of this Professor) and it has dominated the academic publications, shrinking and almost zeroing space for the other researches. Thus, little if any innovation on accounting theory has emerged from the academy. And, when a novelty arises, it seems to cause some unease among scholars.

However, the regulatory agencies, in addition to know researches showing the degree of usefulness of the standards they issue, are in need of theories, concepts, improved knowledge and ideas going beyond purely standardizing purposes, as well as support for new proposals, in order to provide them with a more logical structure and also to promote changes regarding the current standards. This facilitates the issuing process and provides a very significant aid to interpret such standards. Therefore, it is crucial for them, standard setters, besides empirical research, both theory and a well-structured conceptual set. But, instead of looking for them or commissioning them at the natural habitat of these studies, i.e. in the academic world, the very standard setters have produced all these researches and all these developments concerning the conceptual sphere (sometimes, devolution, as in all branches of knowledge, also because they are not necessarily the best prepared people for this).

See, for instance, how many standards and how many proposed standards, drafts, discussion papers, and similar materials have been issued by the International Accounting Standards Board (IASB) and by the Financial Accounting Standards Board (FASB) in the field of accounting theory. Heated discussions have taken place within these agencies and others, as well as in the interaction with the outside world (preparers, auditors, users, and other agents interested in the financial statements) regarding the concept of asset, the time of recognizing it, measurement criteria, taking this discussion to major changes in revenue recognition, in leasing transactions, in measurement of biological assets, in recognition of regulatory assets and liabilities, in recognition of revenue from real estate operations, just to recall some points. How many of these aspects have been discussed in the academic world? Or, at least, how much of this discussion has led to texts written in the academic world? We had some groups providing opinions and suggestions aimed at some of these issues lately, but this is a kind of exception that has always been observed; nevertheless, what has triggered this? The Accounting Standards Committee (CPC)! Regulatory agencies should be importing conceptual researches from the academy, but they stopped being produced. And this is the point in which we must ground ourselves. 
On the other hand, these standard setters should also be producing or commissioning empirical researches on usefulness, weaknesses, costs, and other aspects of the current accounting standards. But standard setters know very little of this research field and the academic world also does not seem to be striving to get closer and take its findings to them. When agreements are established between a regulatory agency and a research institution, they seem to be useful only to be included into the annual reports of activities of these entities. Outcomes from positivist researches are needed and asked by the standard setting body. But they are produced by the academy, without much direction, which has not been translating and bringing them to the world of standard setters.

The most important thing, here, is looking for the reasons for this role reversal. It seems that only the academic institutions are interested in empirical researches, which should be the focus of standard setters, and the latter are striving to develop theory, which should be the focus of the academy.

We know a few reasons for this situation. For instance, a) it is much easier to produce positivist researches (and some of them have a very good quality, unfortunately, not the vast majority), since creativity is a costly and painful parturient activity, without any guarantee of eventual success; b) the need for a thorough accounting conceptual knowledge does not seem to reflect being trained since graduation; c) having opinions of our own and openly advocating for them, so that tests concerning discussion, dialectics, and other means to refine, sieve, eliminate them, looks like something even forbidden nowadays at certain academic environments, and the solution is filling the theses, dissertations, and articles with opinions of other people and avoiding, shamefully, ideas of our own; d) it seems that the spirit of the 19th century has been resumed, i.e. there is a need for demonstrating that accounting is a science, and it also seems that people concluded the only way to do that is by using the methods of natural sciences and taking them as the only ones capable of this proof.

And it is also true that the editors of academic journals savagely complain of lack of quality among materials from this purely conceptual and qualitative trend, because just spouting ideas is not the pathway to the accumulation of theoretical knowledge. The process of criticism is painful, time consuming, risky. In other words, there is a set of reasons (or alleged reasons) showing that conceptual research, aimed at practical use, is a seemingly much more difficult pathway, as well as not very compatible with the academic obsession for publications, with the obligation to obtain a "number of points" for the graduate program, with the assessment model imposed by the Coordination for the Improvement of Higher Education Personnel (CAPES), and passively accepted today by universities, especially the public ones, with deadlines established for obtaining titles etc. Meeting deadlines is more important than improving the quality of what is produced. The vicious circle has been already settled: scholars do not produce conceptual articles that propose changes in practice; when they produce this kind of study, avoid sen- ding it to journals, because they know it will not be accepted for publication, especially the most robust authors, because they feel diminished due to this repeated refusal to publish. The editors receive, in turn, fewer theoretical papers (to use an overused and problematic term, normative papers) and, when these, are received, then, due to the reasons mentioned above, the quality level is poor. Worse, as the number of positivist articles with a good quality level is also not infinite, the accounting journals end up publishing papers on governance, finance, economics, sustainability etc. etc. Sometimes, even on accounting...

Empirical researches with a statistical approach are simpler, faster, and safer (usually, the article may be published regardless of the result obtained), once a particular econometric model has been mastered. And they represent points, even when useless. This not to mention replicating, it is easy and automatic, in most cases. The qualification process of these materials, with assessment concerning the relevance of the issue and, especially, of the result obtained, seems to be still waiting for deployment.

Thus, it is clearly seen why the academic world has turned almost exclusively to the positivist world: convenience, reduction of time and costs, greater assurance of a successful career etc. Everything is driven by a process of personal and institutional assessment criticized by all, but it keeps on its way. The interference of the assessment model for academic programs seems to be leading to this sad point.

In turn, the accounting standard setters, why did they change their role? On the one hand, there seem to lack, something which is more or less obvious, inclination, knowledge, time, and willingness to conduct empirical researches and those full of mathematical formulas. Besides, to a large extent, perhaps they still believe that thinking and having ideas is enough to solve accounting problems. Perhaps many people believe that, by having power in their pen, they hold a higher level of knowledge that does not need evidence demonstrating whether their ideas are really useful in practice for users, whether the costs for obtaining information are compatible with its relevance etc. It is worth mentioning that there still exists, to a significant extent, in the professional world, the idea that the academy is one thing as the real world of practice is another thing. And, worse, this view is also frequently observed in the academic world... That is, the professional and academic worlds have been, to me, very clearly, reversing their roles due to mistakes on both sides.

Notwithstanding, if it is up to one side the initiative to correct these deviations, this side should be the academic environment, since it is less pressed by the pressure of daily life to and it is the place fit to stop to think. I think it is up to the academic world to stop, reflect, philosophize, criticize, and start taking steps so that the roles resume their natural pathways. It is not by chance that Philosophy is the mother of sciences and the origin of the academic world itself. It must have and demonstrate to have the ability to look at the whole without losing sight of details, analyze, criticize, systematize, and propose redirections. This spirit has to be taken by the accounting academic world, too. 
The accounting academic world needs to strengthen the theoretical and conceptual researches and offer them to the normative world. It must also develop empirical tests on the relevance of the current standards to provide feedba$\mathrm{ck}$ for standard setters regarding the rights and wrongs of their decisions, but with close ties to this other side of the world. And it needs to take it all to the world of practice and standard setters by means of a language and a format accessible to them.

There is a need that standard setters are aware that they are not wise just because they have the power, that it is not only from the world of practice that innovative ideas arise, and that we must always think of applying alternatives. And that their offspring, the standards, must be tested, indeed, so that their relevance is demonstrated before deployment. By the way, the ideal is expanding field tests, simulations, and previous applications to companies that concerned with this evolution, so that researches on the usefulness of regulatory changes are provocative of prior analyses promoting their widespread implementation around the world. This could prevent, for instance, the decrease of IASB as for assessing and assigning a comprehensive fair value to the biological assets. (By the way, we must recognize that, seemingly, this agency has, recently, been paying much more attention to these tests, based on simulations performed by companies that propose to do this, including Brazilian ones.)

In other words, both sides have to think through their exchanged roles and unite so that theoretical and normative research, as well as positivist research, can hold hands, being useful to one another and to the development of accounting. However, it is up to the academic world taking the lead in this approach, because it has the obligation to follow up the real world, analyze it, and help redirecting it. For this, it must change its attitude.

\section{References}

Accounting, Economics, and Law: a Convivium. (February 2014). Berlin, Boston: De Gruyter. Recuperado de http:// www.degruyter.com/view/j/ael.

Glover, J. (2014). Have academic accountants and financial accounting standard setters traded places? Accounting, Economics and Law, 4 (1), 17-26. Recuperado de http:// www.degruyter.com/view/j/ael.2014.4.issue-1/issue-files/ ael.2014.4.issue-1.xml.

Macve, R. (2014) Trading places: a UK (and IFRS) comment. Accounting, Economics and Law, 4 (1), 2740. Recuperado de http://www.degruyter.com/view/j/ ael.2014.4.issue-1/issue-files/ael.2014.4.issue-1.xml.

Zeff, S. A. (2014). Some historical reflections on "Have academic and the standard setters traded places"? Accounting, Economics and Law, 4 (1), 41-48. Recuperado de http:// www.degruyter.com/view/j/ael.2014.4.issue-1/issue-files/ ael.2014.4.issue-1.xml. 